\title{
Brasília dialogando com o self
}

\author{
Francisco Angelo Cechin ${ }^{1}$
}

RESUMO - Brasília é a cidade que constitui nossa casa. Uma casa muito bem dividida em compartimentos. A casa é um lugar onde nossa personalidade se forma e de onde retira inúmeras fontes de prazer, alegria e vivências. Queiramos ou não o lugar onde vivemos nos fala à consciência e registra em nossa memória suas influências. É uma pena que, muitas vezes, pela indiferença ou pela constante preocupação pela sobrevivência nossa mente não tem mais acesso ao diálogo relacional que se dá entre o real externo e nosso psiquismo ou self inconsciente. Nossos olhos vêem, nossos sentidos sentem suas mensagens que chegam ao nosso íntimo, mas a consciência é impedida de vivenciar seus efeitos. Este artigo convida a escutar este diálogo, e transformá-lo em criatividade interior e sobre o externo - Brasília.

Palavras chave: Brasília, linhas arquitetônicas, ressonâncias afetivas, símbolos, self.

\section{Brasilia, a dialogue with the self}

\begin{abstract}
Brasília is the town that is our home, and it is a house with well divided compartments. Home is a place where our personality is formed, from where countless sources of pleasure, joy and experiences are taken. Whether we want it or not, the place where we live talks to our consciousness and imprint its influence in our memory. It's a pity that, because of indifference or constant worries on survival, our mind frequently looses the access to the relational dialogue that exists between external reality and our psyche or unconscious self. Our eyes see, our senses feel the messages that reach our inner self, bur awareness is not allowed to experience its effects. This article invites us to hear this dialogue and to let it become inner creativity on the outside that is Brasilia.
\end{abstract}

Key words: Brasília, architectonic lines, affective resonances, symbols, self.

1 Professor de Psicologia do Centro Universitário de Brasília. 
Brasília, cidade sonhada por muitos durante tantos anos. Planejada e edificada por aqueles que quiseram, um dia, ver a esperança de um povo concretizada. Formas e linhas foram expressas na realidade do concreto. Nasceu a capital da esperança! Deitada em berço esplêndido, no coração do Brasil, logo se agigantou, tornandose bela, pasmando o mundo. Sob céu límpido, risonho e formoso, à sombra do cruzeiro do Sul, Brasília foi inaugurada há 46 anos. Síntese de esforços do povo brasileiro, desafiou àqueles que se propuseram a romper os obstáculos, a ocupar o Planalto Central, a redirecionar o desenvolvimento do Brasil.

Hoje, Brasília merece ser novamente admirada, contemplada e descoberta, em seus aspectos artísticos, arquitetônicos e psicológicos As obras de arte são inesgotáveis em suas riquezas de forma e conteúdo. Elas transcendem o tempo, desafiam inteligências mais argutas, despertando emoções mais sensíveis. Elas podem ser sempre novamente descritas, revividas e redescobertas. Muitas vezes a arte supera o seu próprio criador. A obra de arte, no seu todo, pode revelar muito mais do que o autor quis exprimir e que a ele mesmo pode passar despercebido. Os elementos como formas, linhas, cores, símbolos, que o autor usa para a sua obra, são algo que pertencem à História. São elementos riquíssimos de conteúdo humano. A arte, mais do que o autor, expressa os anseios e esperanças de uma época.

Neste momento não nos interessa a Brasília política, social, administrativa, funcional ou econômica, mas a Brasília arte e psicologia. Brasília que toca o espírito.

A arte nos sensibiliza pelas suas cores, formas e conteúdos. Infelizmente o hábito, a rotina, a visão constante de uma mesma realidade, nos familiariza a ela, e a ela nos tornamos insensíveis. Deixa de nos emocionar, de nos despertar sentimentos e sensações que alimentam o espírito. Hoje só o visitante, o estrangeiro exclama: Brasília, cidade fabulosa, florão da América! Nós só vemos os seus defeitos.

Brasília, esse conjunto de formas, linhas, cores e símbolos, tem um significado psicológico. A descrição desse significado faz-se necessária, agora, para rever Brasília mais rica, mais bela, mais encantadora, mais inspiradora de sentimentos e poesia. Descobri-la e criá-la a cada dia é sentir que a nossa vida em seu seio desperta mais amores, desperta nossa riqueza e beleza interior.

As linhas podem ser observadas sob dois pontos de vista: quanto à forma e quanto à posição.

Quanto à forma: retas e curvas; e,

Quanto à posição: verticais. horizontais e inclinadas

As linhas retas nos dão a sensação de precisão, determinação, segurança, objetivos definidos, firmeza e decisão. São linhas mais diretas, agressivas, críticas e auto-afirmativas. São linhas masculinas, com predomínio do racional. O uso abusivo dessas linhas nos dá a sensação de rigidez, rudeza, intransigência e teimosia. 
As linhas curvas, linhas de movimento, pelo contrário, exprimem a delicadeza, a graça, a suavidade, a flexibilidade, a harmonia, a adequação e uma atitude mais aberta e benevolente. São linhas menos agressivas, mais delicadas e femininas, predomínio do emotivo. A graciosidade e beleza da mulher se exprimem em suas linhas curvas. O uso abusivo dessas linhas indica, justamente, a falta de controle racional e a desorganização.

As verticais são linhas em que predomina a altura. Sua expressão é de grandiosidade, pujança, crescimento, progresso, ação, indicando força, orgulho, espírito criador e a sensação do infinito. $\mathrm{O}$ homem sente-se pequeno diante da altura.

As linhas em que predomina o comprimento são as horizontais. Falam de amplidão, de liberdade, de espaço aberto, de tranqüilidade, da posição de descanso e repouso. Sensação de paz, de calma, de monotonia agradável do pôr-do-sol e do amanhecer. O infinito se busca além do horizonte - saudade do longínquo, do distante, do passado, no aberto, a sensação de expansão a liberdade de estar solto.

As linhas inclinadas expressam a queda, quando, no entanto, duas inclinadas se apóiam e se sustentam, formando ângulos, passam à forma piramidal. Sua base é mais sólida, lembram as pirâmides do Egito, que permanecem firmes, seguras e estáveis, atravessando séculos e vencendo as vicissitudes das intempéries. Além da sensação de grandiosidade, sugerem durabilidade, consistência e permanência no tempo e no espaço.

Outras linhas podem ser ainda analisadas em seus aspectos psicológicos. A circunferência, cujos pontos são eqüidistantes de um ponto comum, centro. A expressão e a sensação são as de igualdade, fraternidade, participação de um objetivo comum, ainda a percepção de perfeição, de infinito, de circularidade sem fim e do eterno.

A aspiral, enquanto linha que parte de um ponto e se abre em círculos sempre mais abrangentes, nos fala da acolhida, da abertura, da hospitalidade, da conquista do infinito.

Passeando por Brasília, o que descobrimos com suas linhas? No centro da cidade, na Torre de Tv, no Setor Hoteleiro, no Setor Comercial, predominam linhas verticais. Não podia ser de outra maneira, Brasília representa o Brasil e por isso a grandeza, o trabalho, o progresso, o espírito criador são vistos nas linhas verticais dos prédios do centro da cidade.

As linhas horizontais se sobressaindo no Setor Habitacional expressam uma sensação de paz, de calma, de repouso e de tranqüilidade. Tudo é amplo e aberto. Tudo convida à calma e expansão. Um convite à harmonia, à convivência saudável. O coletivo e o populacional soltos em blocos espalhados pelas áreas verdes das 
superquadras. Nosso espírito não se sente pequeno e quase esmagado como em outras grandes cidades.

As linhas inclinadas, encontramo-las em muitos dos nossos edifícios e monumentos: Torre de Tv, Ginásio de Esportes e a Catedral. Mas é no Teatro Nacional que melhor se evidenciam. Ele nos fala de Brasília como cidade que deve ser sólida, firme e segura. Brasília, capital do Brasil, deve ser a cidade consistente, a cidade que permanece como símbolo através dos tempos. Cidade que falará através dos milênios e será testemunha daquilo que os brasileiros do Século XX realizaram. Apesar dos contratempos e dos conflitos, Brasília deverá passar à posteridade.

As linhas retas e curvas encontram-se distribuídas pela cidade de maneira equilibrada e harmoniosa. Em suas avenidas, um misto de curvo e reto. Quem passa por eles, sobretudo à noite, não deixa de observar a iluminação formando um curvo ondulado e gracioso.

A reta e a curva podem ser vistas em uma série de construções arquitetônicas. Por exemplo: o Palácio do Itamarati, o Palácio da Justiça, o Palácio da Alvorada, o Palácio do Planalto, e nos demais edifícios que, com este, compõem a Praça dos Três Poderes. Nestes quatro últimos, encontramos um conjunto de linhas retas e curvas produzindo efeitos estéticos agradáveis, constituindo-se até mesmo em símbolos de Brasília. Temos, então, um misto equilibrado de sensações: de precisão, de segurança, de decisão e auto-determinação, com delicadeza, a flexibilidade e a harmonia. A agressividade fundindo-se com a delicadeza e o emocional. De um lado a sensação da força máscula e de outra a graciosidade da beleza feminina. Nada parece forçado. O olhar desliza suave por essas linhas sem o impacto do muito reto e da desorganização. Interessante observar que no Congresso Nacional encontram-se manifestadas todas as linhas anteriormente analisadas .

O círculo encontrado nos retornos, no Palácio dos Esportes, na Catedral, no Plenário e alhures, nos conclamando para igualdade, fraternidade e a participação dos bens comuns.

No Campo da esperança, a espiral, a sensação de que nem tudo está acabado. Mas, que ali é o ponto que nos leva a participar do infinito cósmico. Ali ninguém está perdido - é o próprio infinito que nos acolhe e que abre a hospitalidade.

$\mathrm{Na}$ Catedral, as linhas curvas. O círculo como ponto de convergência e divergência para todas as direções do Brasil. As colunas que se erguem nos dão a impressão de que tenham partido das entranhas da terra brasileira, emergida ali, para juntas subirem aos píncaros e novamente se distenderem sobre os mesmos pontos de partida. É o encontro da oração e na fraternidade, a confluência das crenças da gente brasileira que se concentra para adquirir mais vigor e multiplicarse em luzes benéficas para todos. 
Hoje temos uma ponte que nos orgulha, considerada a mais bela do mundo. Ao passarmos por ela sentimos a leveza e a firmeza de sua estrutura, abraça-nos três vezes com seus arcos que emergem das águas nos sustentam e se elevam aos céus e novamente submergem nas águas, símbolos da eterna circularidades dos astros e do eterno retorno da vida. Brasília ainda nos acolhe e enche de dádivas com seus parques, pontos de lazer a beira do lago, dias ensolarados, céus cheios de nuvens, a terra cheia de fontes guardando incógnitas e sonho de vida. As manhãs, pôr-de-sol e os luares dão a Brasília uma aura e esplendor que a caracteriza.

Brasília foi considerada ultimamente como a cidade com melhor qualidade de vida. Vista, assim, em suas linhas, cores, Brasília, torna-se um mundo encantado para nossos olhos e nosso interior.

E nas cores? O verde é a cor da esperança e a cor da natureza. É a mais repousante das cores. Lembra bosque, relva, campos, umidade frescura. Impele a adaptação efetiva com a vida. É a cor resultante da combinação de uma cor quente e uma fria. Dá-nos a sensação do morno, do relaxante e do tranqüilo. O verde quem não o vê e sente em Brasília? Nenhuma cidade tem tantos gramados. $\mathrm{O}$ verde dá o tom da cidade. Nossos olhos se distendem e se relaxam. Apesar do impacto causado pela frieza e dureza do cimento, o verde nos afaga, acalenta e ameniza.

O azul, todos conhecem a sua simbologia, lembra a água e amplidão. É a cor da serenidade e da quietude. Estimula a meditação, a reflexão e a contemplação. Exprime a doçura, a bondade, o sentimento e os amantes.

Sentimos o vermelho da terra de Brasília, cor de força, de calor, da garra dos pioneiros, talvez, que aos poucos vai sendo coberta pelo verde, mas ainda pode ser vista e permanece ali embaixo da grama, e irrompe quando o solo é rasgado.

A água, um dos símbolos mais cheios de significados, nos fala da vida e de tudo que cresce. A água limpa sacia a sede. Da água se originou a vida e na água o homem passa imerso durante seus primeiros noves meses de existência, na água encontra grandes fontes de lazer e prazer.

A capital do Brasil nasceu à beira d'água. $O$ grito da independência às margens do Ipiranga. Brasília, também, teve o seu Natal à beira do lago que parece abraçála e trazê-la em seus braços. Há inúmeras fontes, cascatas, espelhos d'água em toda Brasília. É componente significativo do conjunto arquitetônico de Brasília. Convida à reflexão, à purificação e cristalização de idéias. Vivifica energias. Estimula a reabilitação de forças e objetivos da vida.

E o diálogo continua. Brasília, nas suas linhas, nas cores e símbolos, há muito por se descobrir. Qual tal lançarmo-nos a esse empreendimento? 